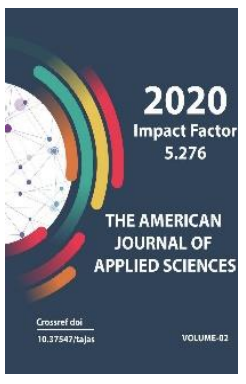

Copyright: Original content from this work may be used under the terms of the creative commons attributes 4.0 licence.

\section{Research Of The Boundary Of The Section Of A Photo Receiver Based On Mos pCdTe / CdO Structures}

\author{
Sh.B.Utamuradova \\ Research Institute Of Semiconductor Physics And Microelectronics At \\ The National University Of Uzbekistan Named After Mirzo Ulugbek, Tashkent, Uzbekistan

\section{S.A.Muzafarova} \\ Research Institute Of Semiconductor Physics And Microelectronics At The National University \\ Of Uzbekistan Named After Mirzo Ulugbek, Tashkent, Uzbekistan
}

\title{
ABSTRACT
}

In this work, we investigated an intermediate layer in the structure of a photosensitive MOS structure $\mathrm{nCdO} / \mathrm{pCdTe}$. X-ray phase analysis shows that the intermediate layer between Mo and pCdTe is rather complex in composition. It contains dichalcogenides - three oxide $\mathrm{MoO}_{3}$ and a thin layer of a composite material with the composition of ditelluride $\mathrm{MoTe}_{2}$. According to X-ray diffraction measurements, the total thickness of the intermediate layer is no more than $\sim 200 \AA \hat{\text {. It }}$ was shown that in the $\mathrm{nCdO} / \mathrm{pCdTe}$ structure the base material CdTe mainly consists of a homogeneous cubic modification layer.

\section{KEYWORDS}

Intermediate layer, photosensitivity, gas transport, interfaces, dichalcogenides, X-ray diffraction analysis, structure.

\section{INTRODUCTION}

Compounds A2B6 possess a successful combination of electrical and photoelectric properties, high photosensitivity, ability to electroluminescence, high thermal and radiation resistance, and a fairly simple technology for producing large-area films . Among the $\mathrm{A}_{2} \mathrm{~B}_{6}$ compounds, cadmium telluride ( $\mathrm{CdTe}$ ) stands out for its electro physical, optical and photoelectric properties, as well as the possibility of obtaining oriented 
polycrystalline films on its basis using a simple technology. This makes it possible to use CdTe films as a base material in the creation of efficient photovoltaic devices, including photo converters for ground-based and space applications and a wide range of photo detectors capable of operating under extreme conditions. The band gap of cadmium telluride (1.5 eV) ensures operation without cryogenic cooling. Molybdenum (Mo) is a noticeable back contact for CdTe with a work function of $4.6 \mathrm{eV}$ [1 ]. Compared with other rear contacts, Mo is more cheap and affordable material as the substrate and as the ohmic to contact. This is very important for reducing the series resistance of photosensitive structures and solar cells.

Recent studies have shown that an intermediate layer is formed in a heterogeneous metal-semiconductor system [2-4 ], which can significantly affect the output parameters of the structure. In this case, the atomic and electronic structure of the metal significantly affects the physicochemical processes occurring at the interface: metal semiconductor. Since the interaction between a metal and a semiconductor is determined not only by the type of chemical bond of the semiconductor, but is largely determined by the structural - morphological characteristics of a thin metal layer. As a result, they affect the intensity of diffusion processes and phase formation in the transition layers in the diode structure. Therefore, the study of the real structure of photosensitive structures is not only of fundamental scientific, but also of practical interest.

\section{SAMPLES AND RESEARCH METHODS}

Films of $p$ CdTe were obtained on a Mo substrate at a temperature $\mathrm{Tn}=620 \mathrm{oC}$ and $\mathrm{a}$ source $\mathrm{T} n=950^{\circ} \mathrm{C}$ and a hydrogen rate $\mathrm{H}_{2} \mathrm{~V}_{\mathrm{H}_{2}}$ $=2$ liter $/ \mathrm{h}$. Metallographic studies of the film surface showed that the film consists of blocks of micro crystals with a thickness of 20-60 $\mu \mathrm{m}$. At $\mathrm{T}_{\mathrm{n}}=620^{\circ} \mathrm{C}\left(\mathrm{T}_{\mathrm{u}}=\right.$ const, $\mathrm{V}_{\mathrm{H}_{2}}=$ const $)$, the obtained $\mathrm{CdTe}$ films have a shiny surface with an excess of tellurium Te on the surface. And ssledo Bani show that during the synthesis largebloc polycrystalline CdTe films due re evaporation volatile component $\mathrm{Cd}$ in a gas phase system produces free tellurium atoms Te , which interact with the residual oxygen in the reactor to form a thin high-resistance layers Those $\mathrm{O}_{2}$ between a layer of $\mathrm{p} \mathrm{CdTe}$ and $\mathrm{n}$ $\mathrm{CdO}$. The $\mathrm{TeO}_{2}$ oxide layer passivity's surface states in grain boundaries [5-7], which leads to a decrease in surface recombination and a significant increase in the lifetime of no equilibrium charge carriers to several tens of microseconds [8].

In order to elucidate the real structure of the MIS structures of $\mathrm{nCdO} / \mathrm{pCdTe}, \mathrm{X}$-ray phase analysis was carried out on a DRON-2 setup ( $\mathrm{Cu}$ - radiation, $\mathrm{Ni}$ - filter). The information depth in this case is $1-2 \mu \mathrm{m}$.

To study the structure of the Mo - CdTe interface, the cadmium telluride film was separated from the molybdenum substrate and the surface of the film adjacent to the substrate and the substrate adjacent to the film was studied separately.

It was found that the initial high- purity molybdenum substrate does not contain oxides on its surface. Oxide - dichalcogenides trioxide $\mathrm{MoO}_{3}$ and MoTe 2 appears in 
the process of synthesis, as a result of the contact of a heated molybdenum substrate as a result of chemical interaction with residual oxygen $\mathrm{O}_{2}$ in the system $[9,10]$.

Films pCdTe had a resistivity $\rho \square \approx \square 10^{5}$ $-\square 10^{7} \Omega \square \cdot \square$ with $\mathrm{m}$ and minority carrier lifetime of the order of $\tau=10^{-7}-10^{-6} \mathrm{~s}$. The thickness of the $p$ CdTe films was $\sim 30 \mu \mathrm{m}$. The grain sizes of polycrystalline pCdTe are in the range from 100 to $150 \mu \mathrm{m}$; the grains cover the entire thickness of the film. For transparent th layer I Cd O was used magnetron sputtering method [ 11,12 ] .If dusting layer I as a target are used, respectively, pure cadmium $\mathrm{C} d$. Thickness $C d O$ was $120 \div 150 \mathrm{~nm}$. In a vacuum installation VUP - 5M deposited thin films CdO by magnetron sputtering at a constant rated current at a substrate temperature of $300^{\circ} \mathrm{C}$. Method thermal vacuum evaporation deposited $\boldsymbol{W}$-shaped upper ohmic contact of indium In a thickness of $50 \mathrm{~nm}$ by vacuum deposition with an area w of $S \approx 6 \mathrm{~mm}^{2}$ to $S \approx 1$ $\mathrm{cm}^{2}$. Such a structure had a reverse current of coefficient $\mathrm{k}=\mathrm{I}_{\mathrm{p}} / \mathrm{I}_{\text {arr }}=10^{3} \div 10^{4}($ at $\mathrm{V}=10 \mathrm{~V})$ To clarify the real structure of the $\mathrm{nCdO} / \mathrm{pCdTe}$ structure, X-ray phase analysis was also performed. The information depth was $300 \mathrm{~nm}$

\section{Results And Their Discussion. X-Ray Structural Analysis.}

The lattice parameters of CdTe are calculated by the formula e

$$
\mathrm{d}^{2}=\frac{\mathrm{a}^{2}}{\hbar^{2}+\mathrm{k}^{2}+\mathrm{l}^{2}}=\frac{\mathrm{a}^{2}}{\mathrm{~N}}
$$

and the Wolfe - Bragg formula :

$$
\operatorname{Sin} \theta=\frac{\pi}{2 \mathrm{a}} \mathrm{N}
$$

Wherein, $\theta \square$ - Breggovsky angle determined by radiographs s index Miller. $\theta \square$ was: $6.485 \AA$, $6.486 \AA$, $6.487 \AA$. The relative calculation error was $0.062,0.077,0.093 \%$, respectively. $\mathrm{N}=\hbar^{2}+\mathbf{k}^{2}+\mathbf{1}^{2}$

$\sim(2 \div \square 5) \cdot 10^{-9} \mathrm{~A}$ and a rectification

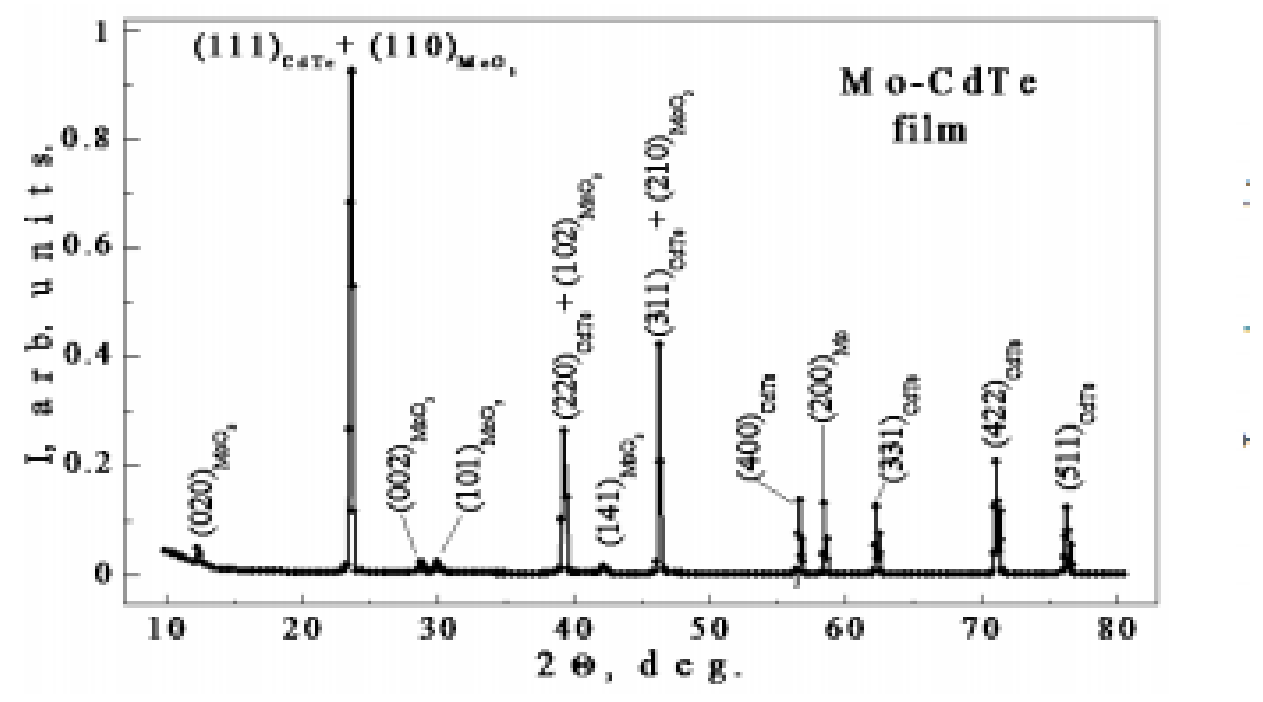

Fig. 1. X-ray diffraction pattern of the Mo-CdTe structure . 
The crystallite size increases to $1-2 \mu \mathrm{m}$ and has a pronounced triangular shape, characteristic of the cubic phase modification ( Fig. 2 ).
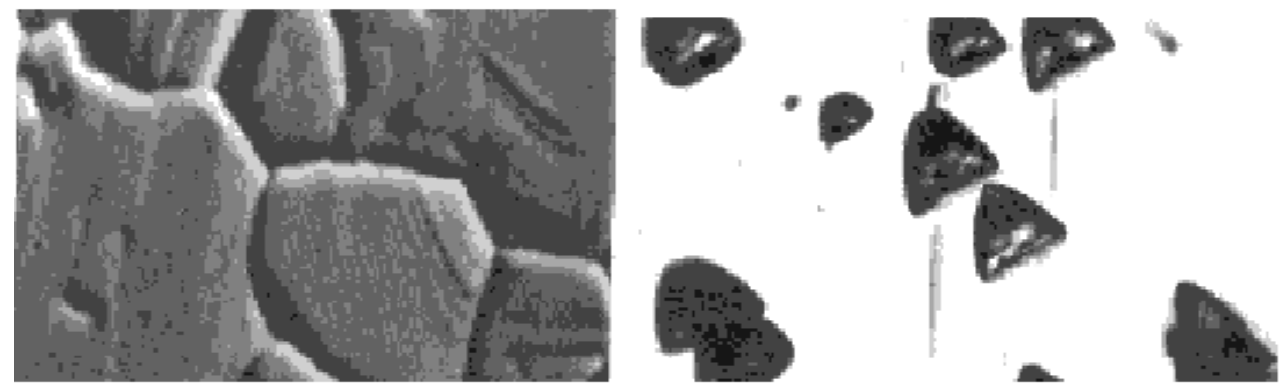

Figure: 2 . Micrograph of the surface of CdTe films on a molybdenum substrate,

unpolished (a) etched with an E - Ag -1 etchant (b) the surface of films M: $1 \mathrm{cm:} 25 \mu \mathrm{m}$.

Activation analysis [ 1 ] and Auger measurement - spectroscopy [ 13 ] show that the films telluride cadmium is composed of cubic-type portions spalerita modifications (Table.1).The results of X-ray structural analysis of the nCdO / pCdTe structures in comparison with the data and work [7] are presented inTable 1.
Table 1. X-ray structural analysis of nCdO / pCdTe structures

By -cubic modification, $\mathrm{C}$ - a strong reflection, ff be a weak reflection.

\begin{tabular}{|c|c|c|c|c|c|c|c|}
\hline \multicolumn{3}{|c|}{ CdTe [17] } & \multicolumn{2}{c|}{ M about Te 2 } & \multicolumn{2}{c|}{ MoO 3 } \\
\hline $2 \theta^{\circ}$ & J & lattice & peak & $2 \theta^{\circ}$ & J / peak & $2 \theta^{\circ}$ & J / peak \\
\hline 22 & 3.74 & K & C & 25 & $3.54, \mathrm{cl}$ & & \\
\hline thirty & 2.97 & K & Cl & 29 & $3.1, \mathrm{cl}$ & & \\
\hline 38 & 2.29 & K & C & 37 & $2.41, \mathrm{Cl}$ & & \\
\hline 40 & 2.29 & K & C & & & & \\
\hline 43 & 1.22 & K & Cl & 42 & $2.14, \mathrm{Cl}$ & 42 & 2.2 sl \\
\hline 46 & 1.95 & K & C & & & & \\
\hline 54 & 1.25 & K & Cl & & & 59 & 1.6, C \\
\hline 57 & 1.62 & K & C & & & & \\
\hline 62 & 1.44 & K & C & & & & \\
\hline
\end{tabular}


CdTe films. On diffract gram (Fig.3) clearly distinguished reflexes Bragg angles corresponding essentially telluride cadmium cubic modification and compounds $\mathrm{nCdO}$. The X-ray diffraction pattern shows that CdTe films are synthesized in the crystallographic directions (111), (220), (311), (400). Similar X-ray diffraction data were also obtained by the authors of other works, in which the films were grown by methods of electrodepositing [14], laser vapor deposition [15], and sublimation in a closed volume [16]. Reflexes with indices (111) in the radiograph are the most intense. This means that this plane orients the structure of the CdTe films as sphalerite. The presence of other peaks with reflections (220), (311), and (400) indicates that the CdTe films have a cubic face-centered lattice with a coordination number of $12[5,6]$.

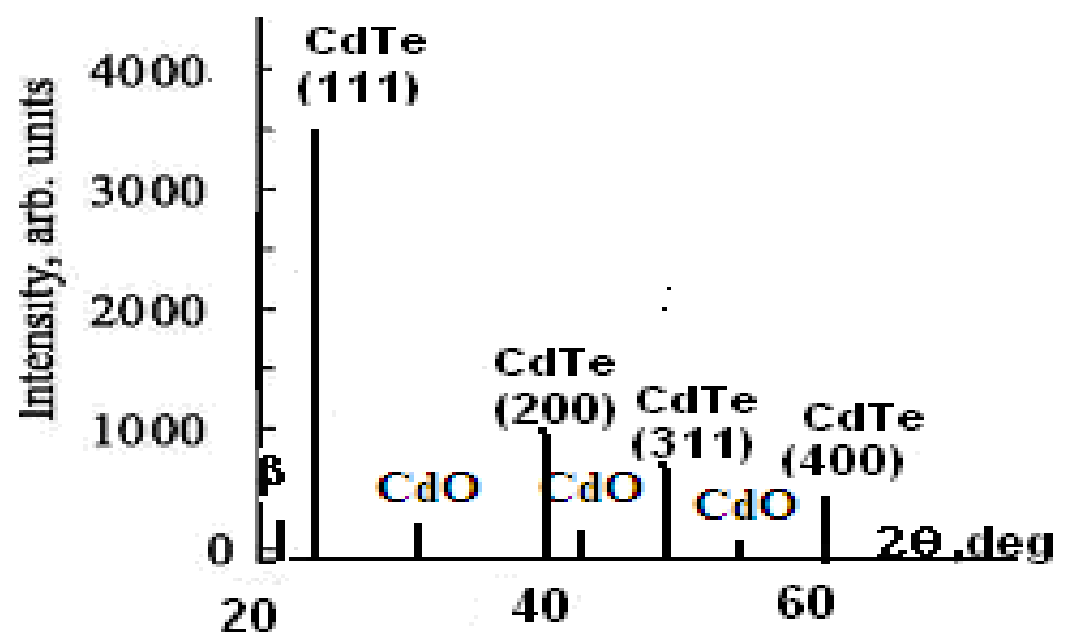

Fig.3.Diffract gram structure nCdO / pCdTe in of radiation copper anode when

focusing on Bragg-Brentano.

The results of the indexing and fingerprinting comparison with the set of standard X-ray diffraction patterns ASTM [7] show that the grown CdTe films of the cubic modification are homogeneous. This also confirms the calculated Miller indices: 6.486 Á,

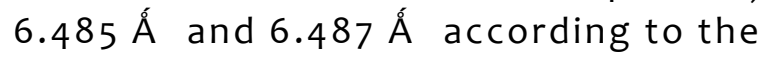
formula $\mathrm{N}=\mathrm{h}_{2}+\mathrm{k}_{2}+\mathrm{I}_{2}$ for three large peaks in the X-ray diffraction pattern, which coincide well with the lattice constant $a=6.482$ Á of cadmium telluride of the cubic modification. The relative error in calculating the Miller indices was, respectively, 0.062;0.077 and $0.093 \%$ for the indicated peaks on the roentgenogram.

Intermediate layer Mo - pCdTe. Dichalcogenid have the chemical formula $M X 2$, where $M$ is a transition metal. Bulk dichacogenide is a semiconductor with an indirect band gap, but it turns into a semiconductor with a direct band gap when the crystal thickness decreases to a monolayer. Since monolayers of such materials also efficiently absorb and emit light, they are ideal for creating various since dichalcogenide ditelluride molybdenum MoTe $_{2}$ (Fig.4) is a semiconductor material, it may be n-type or $\mathrm{p}$ type. Properties and Interface and Mo - MoTe - CdTe strongly dependent on the conductivity 
type MoTe 2 optoelectronic devices, for example, light emitting diodes or solar cells.

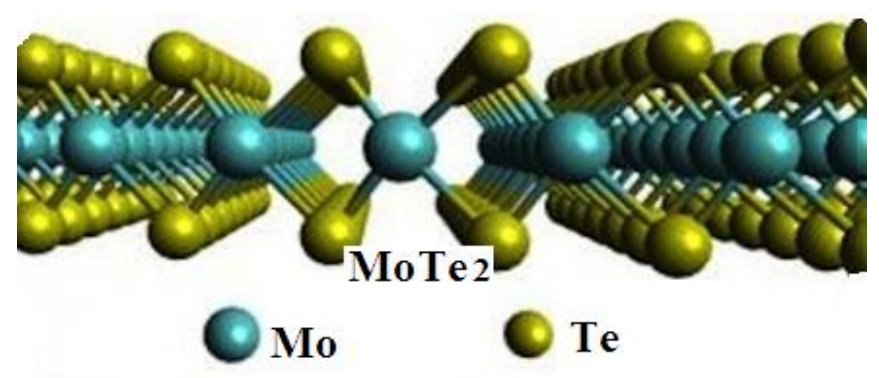

Figure: 4 . Dichalcogenide of molybdenum ditelluride $\mathrm{MoTe}_{2}$

In and Interface metal-semiconductor Mo $\mathrm{MoTe}_{2}$ can be both ohmic and rectifying type , in exactly STI depending on the metal $\left(\Phi_{\mathrm{m}}\right)$ and the operation of the semiconductor output (Фs ). As shown in [13] The pCdTe intermediate layer between the Mo metal contact and the pCdTe semiconductor - dichalcogenide , significantly determines the output parameters of the structure (device). Therefore, the study of the composition and properties of the intermediate layer in any structure is not only of scientific but also of great practical interest.

On. (Fig.4) shows the real structure of the Mo - CdTe boundary.

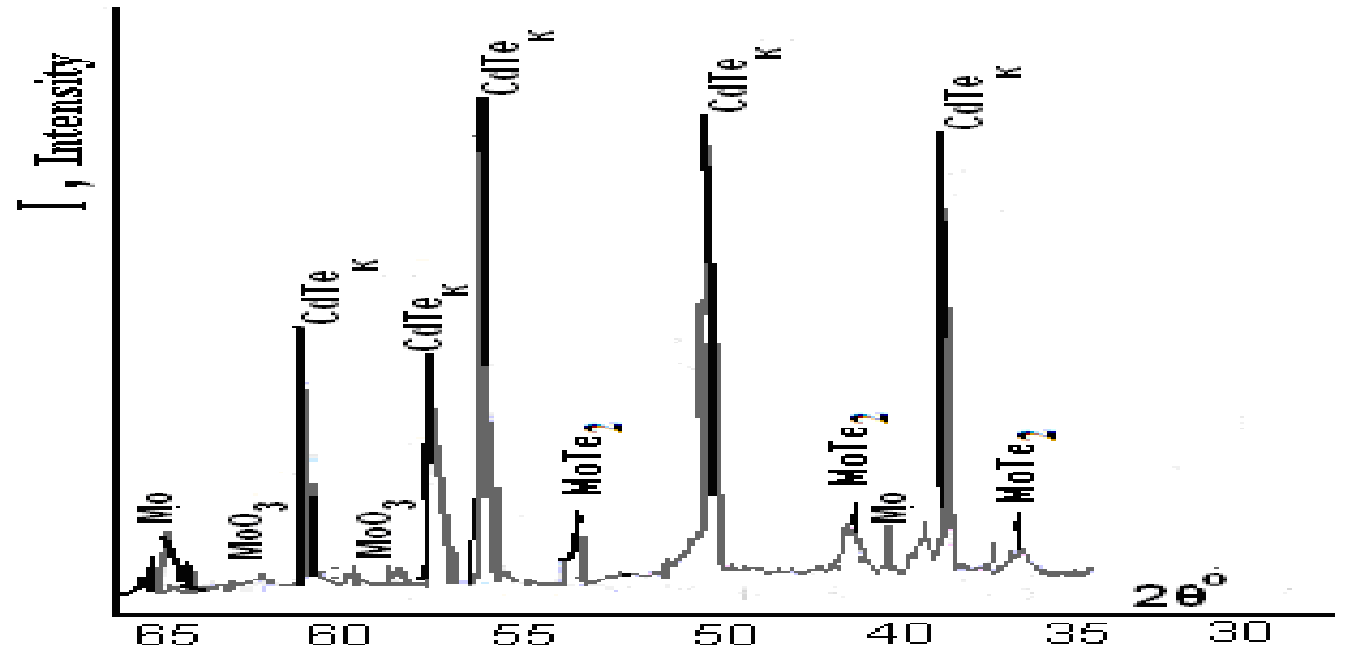

Fig. 5. Real structure of the boundary Mo-CdTe.

It was found that the initial molybdenum substrate comprises on its surface not dichalcogenides . Trioxide $\mathrm{MoO}_{3}$ and ditelluride molybdenum $\mathrm{MoTe}_{2}$ appears during the synthesis, results in the contact of the heated substrate molybdenum residual oxygen in the system. Dichalcogenides $\mathrm{MoO}_{3}$ 
(Fig.5.) And MoTe (Fig.6.)Also manifests itself as a semiconductor $\mathrm{n}$ - type $[8,17]$.

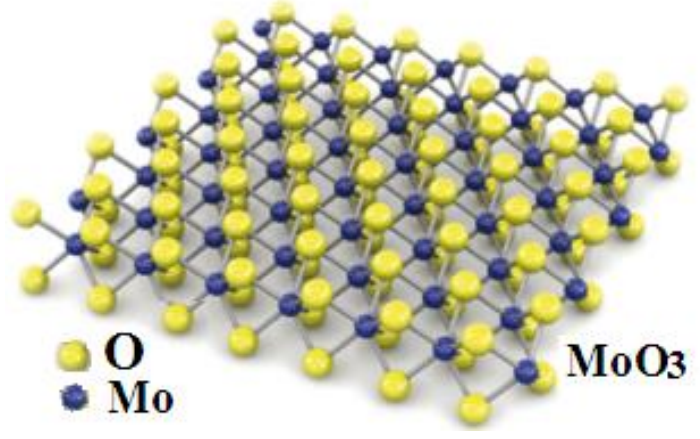

Figure: 6 . Dichalcogenide of molybdenum trioxide $\mathrm{MoO}_{3}$.

Studies show real structures structure nCdO / pCdTe by X-ray phase analysis, and their structure is based circuit (Fig . 7.), Which has the following sequence: $\mathrm{Mo}+\mathrm{MoO}_{3}+\mathrm{MoTe}_{2}+$ $\mathrm{CdTe}+\mathrm{TeO}_{2}+\mathrm{CdO}+\ln$.

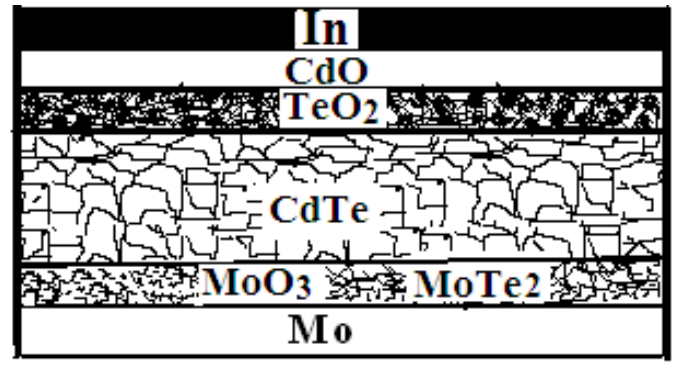

Fig. 7 . Diagram of the real structure of nCdO / pCdTe structures

$$
\mathrm{Mo}+\mathrm{MoO}_{3}+\mathrm{MoTe}_{2}+\mathrm{CdTe}+\mathrm{TeO}_{2}+\mathrm{CdO}+\mathrm{In}
$$

\section{CONCLUSION}

Spent $x$-ray phase analysis of the structure nCdO / pCdTe showed that the structure formed by the intermediate layers between the metal substrate Mo molybdenum - CdTe mainly semiconductor dichalcogenide trioxide $\mathrm{MoO}_{3}$ and ditelluride molybdenum $\mathrm{MoTe}_{2}$ at the interface of $\mathrm{p} \mathrm{CdTe}$ and $\mathrm{nCdO}$ oxide $\mathrm{TeO}_{2}$, which in the structure exhibits a dielectric layer in the MOS structure. It is shown that the base material mainly consists of cubic CdTe. The structure, the external shape of the microcrystal's and the band gap of molybdenum trioxide $\mathrm{MoO}_{3}$ are very sensitive to the technological conditions of gas transport deposition, the synthesis temperature and the composition of the gas 
transport medium, of CdTe films in a stream of hydrogen $\mathrm{H}_{2}$,

At a synthesis temperature of $800{ }^{\circ} \mathrm{C}$, under the action of hydrogen vapor and residual oxygen $\mathrm{O}_{2}$ in the gas transport medium, molybdenum trioxide $\mathrm{MoO}_{3}$ transforms into the main orthorhombic structure of microcrystals. At high temperatures of $900^{\circ} \mathrm{C}$ and $1000^{\circ} \mathrm{C}$ of gas transport deposition at the Mo-CdTe interface, ditellurides different modifications: hexagonal symmetry and trigonal / rhombohedra crystal system at $1000^{\circ} \mathrm{C}$. Dichalcogenide $\mathrm{s}$ trioxide, molybdenum $\mathrm{MoO}_{3}$ and ditelluride molybdenum $\mathrm{MoTe}_{2}$ are wide-band semiconductors as the $\mathrm{n}$ - type and as a p-type, which depend on the process parameters layers growing $\mathrm{CdTe}$ on a molybdenum substrate.

\section{REFERENCES}

1. Sh.A. Mirsagatov, S.Kh. Shamirzaev , M.A.Makhmudov, S.I.Sadykov. Heliotekhnika, 1998. No. 5, p20-25.

2. V.I.Strikha , E.V. Buzaneva . Physical foundations of the reliability of metalsemiconductor contacts in integrated electronics. // M. Radio and communication, 1987, $254 \mathrm{p}$.

3. Y. Breza, EF Venger, RV Konakova. Ya.Ya. Kudrik, O.S. Litvin, P.M. Litvin, V.V. Milenin . // Surface, -1998, No. 5, p. 110-127.

4. A.E.Belyaev, N.S. Boltovets, V.N. Ivanov, A.B. et al. // FTP, 2009, Vol. 43, No. 11, pp. 1468-1472.

5. B.F. Or Mont., Introduction vfiz .x imiyu and crystal chemistry of semiconductors. M., High School, 1968. - 203 p .
6. Yu.K. Yezhovsky ,, I.P. Kalinkin, K.K. Muravyova, V.B. Aleksovsky ., Synthesis of epitaxial films to CdTe. News of the USSR Academy of Sciences. Neorganicheskie materially.- 1973- T .9.-№ 7, with 1115-1 120.

7. American Society for Testing of Materials., ASTM-Powder diffraction tile search manner alphabetical listing and search section of frequently Encountered phase's inorganic. USA 1976.

8. Crystal chemical and physical properties of semiconductor substances. Directory. Publishing house of standards. Moscow, 1973, 102 s.

9. Domashevskaya E. P. Ivkov S. A, Al Khaylani Hasan Ismail Dambos Radam Ali Obaid Radam, Ryabtsev S. V. / Features of the formation of thin layers of molybdenum disulfide MoS2 on metallic molybdenum at different temperatures // Condensed media and interfacial border, 2018 T. 20, number 1. p . 56-65

10. Domashevskaya E.P., Ivkov S.A., Al Khaylani Khasan Ismail Dambos, Ryabtsev S.V. / Features of the structure and optical properties of molybdenum trioxide $\mathrm{MoO}_{3}$ obtained under different technological conditions of gas transport deposition // Inorganic materials, 2019 , volume 55, no. 52-61

11. Danilin B.S. Mikaychev V.E. Syrchin V.S. magnetron sputtering systems Electronics industry 1976, no. 5 p. 43

12. Danilin B.S. Obtaining thin-film layers using a magnetron ion sputtering system. Foreign radio electronics 1978, No. 4, pp. 87-104.

13. A.A. Aliev, Sh.A. Mirsagatov, S. A. Muzafarova , A. A. Abduvayitov . Sat. Proceedings of the International Conference "Fundamental and Applied 
Problems of Physics" , Tashkent. 18-19 November 2004, pp. 211-214.

14. Bonilla Silvia, Enrique A. Dachiele. Electrochemical deposition and characterization of CdTe polycrystalline thin films. / / Thin solid films . - 1991-T. 204 №2. $r$. 397-403.

15. A, A. Compaon Bhat . C.Tabory ,. S Liu, M.Nquyen ,. A. Audinli . LHTsien, RG Bohn Fabrication of CdTe solar cells by laser- drivin physical vapor deposition. Solar Cells. -1991-V30-\# 1-4.p.7988.

16. Gil Yong Chung Sung Chan Park, K urn Cuo , Byung Tae Aim. Electrical properties of CdTe films prepared by close - spaced sublimation with screen printed source layers.// J Appl . Phys . 1995, V 78- number $9, \mathrm{p} \cdot$ 5493-5498.

17. Physical and chemical properties of oxides. Directory under born in units . G.V.Samsonova. M., Metallurgy, 1978. 